\title{
Goat Milk Feeding Causes an Increase in Biliary Secretion of Cholesterol and a Decrease in Plasma Cholesterol Levels in Rats
}

\author{
I. López-Aliaga, M. J. M. Alférez, M. T. Nestares, P. B. Ros, M. Barrionuevo, and M. S. Campos \\ Department of Physiology and Institute of Nutrition and Food Technology, \\ University of Granada, E-18071 Granada, Spain
}

\begin{abstract}
The hypocholesterolemic effect of goat milk with respect to cow milk observed in a previous study led us to examine the influence of goat and cow milk in the diet on certain aspects of biliary physiology in normal rats. The fat content in all diets was $10 \%$ but the lipid quality was varied: the standard diet was based on virgin olive oil, and the other 2 diets included fat obtained from lyophilized cow milk and goat milk. We characterized the bile secretion, including biliary phospholipid, cholesterol, and bile acid outputs, the interrelation between bile acids and bile lipids, and the lithogenic index. The consumption of goat milk in the diet, compared with that of cow milk, caused an increase in the biliary secretion of cholesterol together with a decrease in plasma cholesterol concentration, whereas values for bile phospholipids, biliary acid concentrations, and the lithogenic index remained normal. Moreover, consumption of this type of milk decreased plasma triglyceride concentration and therefore had a positive effect, similar to that of olive oil (standard diet), on the lipid metabolism; hence, it may be recommended for consumption by the general population.
\end{abstract}

(Key words: goat and cow milk, dietary fat, biliary lipids, rats)

Abbreviation key: AIN = American Institute of Nutrition, $\mathbf{M C T}=$ medium-chain triglycerides, $\mathbf{S F A}=$ saturated fatty acids.

\section{INTRODUCTION}

The consumption of fat milk, from all sources, has been estimated to contribute 13.6 to $20.2 \%$ of total fat intake per person per day in Spain (MAPA, 2004). Thus, dairy products are an important source of fat in the diet. However, the consumption of such products has decreased during the last decade because of their negative image with respect to health. The association of

Received July 15, 2004.

Accepted November 17, 2004.

Corresponding author: M. S. Campos; e-mail: marga@ugr.es. dairy food intake with the risk of coronary heart disease has been a long-standing topic of discussion (Berner, 1993). In general, this negative effect has been attributed to high blood cholesterol concentrations arising from the saturated fatty acids (SFA) present in these foods. However, the type of SFA should be taken into account when considering atherogenic effects, as medium-chain triglycerides (MCT) do not produce this effect (During et al., 2000). In corroboration of this, in previous studies by our research groups, we have found that the consumption of goat milk, which is rich in MCT, leads to a decrease in cholesterol plasma concentrations in rats (Alférez et al., 2001).

Cholesterol from the diet is transported in chylomicrons and chylomicron remnants directly to the liver (Redgrave, 1983), where it may be excreted via the bile as unesterified cholesterol or (after conversion) as bile acids; bile acid synthesis is a major pathway for the elimination of cholesterol. Alternatively, it may be stored in the tissue as cholesteryl ester or returned to the circulation in new lipoprotein. Alterations in hepatic cholesterol metabolism in response to different types of dietary fat have been demonstrated in a number of studies. It is likely that the changes in hepatic cholesterol metabolism, which occur when animals are fed high-fat diets, alter the processing of the different types of chylomicron by the liver, and consequently the proportion of dietary cholesterol excreted in the bile (Bravo et al., 1998).

Digestion and absorption of dietary fat require the presence of an adequate concentration of bile acids in the small intestine. In different physiological and experimental situations, bile lipid secretion (cholesterol and phospholipids) seems to be determined by the secretion of bile acid (Nakano et al., 1990). Additionally, diet can induce changes in the cholesterol:phospholipid ratio (Turley and Dietschy, 1988).

For the purpose of intestinal lipid absorption, a variable flux of bile salt and cholesterol takes place from the liver into the duodenum via the biliary tract. Although most of these steroids are recovered by reabsorption in the lower intestine, by temporarily leaving the "milieu interne" of the organism, they challenge the animal's capability to maintain the homeostasis of its steroid 
pool. Hence, to understand the metabolism of cholesterol and bile salts, it is useful to perform an analysis of bile flow and steroid concentration in the bile at short intervals in vivo.

The aim of this study, thus, was to investigate the hypocholesterolemic effect of the dietary consumption of goat milk and to determine whether the biliary output of cholesterol contributed to this effect.

\section{MATERIALS AND METHODS}

\section{Animals}

We studied 28 rats (male rats, Rattus norvegicus, Wistar albino breed), with a mean initial body weight of $262.5 \pm 5.7 \mathrm{~g}$ (10 to $11 \mathrm{wk}$ old), purchased from the University of Granada Laboratory Animal Service. All experiments and surgical procedures were performed according to international guidelines. The experimental protocol was approved by the Ethics Committee of the University of Granada.

\section{Diets}

The diets and mineral and vitamin supplements were prepared according to the recommendations of the American Institute of Nutrition (AIN; Reeves et al., 1993), except that the level of fat in the diets was $10 \%$ rather than $5 \%$. The standard diet was prepared using virgin olive oil as the source of fat (10\%) and casein as the protein source $(20 \%)$. The milk-based diets were created with lyophilized cow or goat milk. The analysis of milk lyophylates is shown in the footnote to Table 1. The necessary quantities of lyophilized goat or cow milk were used to obtain a diet with a $10 \%$ fat content. To obtain the $20 \%$ protein content (as recommended by the AIN; Reeves et al., 1993), the diets were supplemented with casein (Musal \& Chemical, Granada, Spain), using $12.40 \mathrm{~g}$ of casein/ $100 \mathrm{~g}$ for the cow's milk diet and $14.50 \mathrm{~g}$ of casein/100 $\mathrm{g}$ for the goat's milk diet, as the protein provided by the lyophylate used for the milk-based diets was insufficient.

The mineral corrector was prepared according to AIN recommendations (Reeves et al., 1993) for the standard diet and to our own specifications for the milk-based diets. These specific correctors were formulated taking into account the mineral content of the lyophilized milks supplied to the rats to meet the mineral content recommendations of the AIN (Reeves et al., 1993). The lactose content of the milk diets was subtracted from the total carbohydrate content of the standard diet, and wheat starch and sucrose were added corresponding to the difference (Table 1).

The following analyses were made of the diets and lyophylates: Dry matter (AOAC, 1990), calcium, iron,
Table 1. Composition of the experimental diets.

\begin{tabular}{lrrr}
\hline & \multicolumn{3}{c}{ Experimental diet $^{1}$} \\
\cline { 2 - 4 } $\begin{array}{l}\text { Component } \\
\text { [g/kg of diet (DM basis)] }\end{array}$ & Diet S & Diet C & Diet G \\
\hline Protein (casein) & 210 & 204 & 205 \\
Fat (olive oil; MCT ${ }^{3}=0 \mathrm{~g}$ ) & 100 & 0 & 0 \\
Fat (cow's milk; MCT = 20.9 g) & 0 & 99 & 0 \\
Fat (goat's milk; MCT = 33.7 g) & 0 & 0 & 94 \\
Fiber (micronized cellulose) & 51 & 52 & 49 \\
Mineral specific supplement & 36 & 35 & 36 \\
Vitamin specific supplement & 10 & 10 & 10 \\
Choline chloride & 2 & 2 & 2 \\
L-Cysteine & 1.8 & 1.8 & 1.8 \\
Wheat starch & 491 & 304 & 310 \\
Sucrose & 100 & 100 & 100 \\
Lactose & 0 & 195 & 190 \\
kJ & 17,940 & 18,844 & 18,771 \\
\hline
\end{tabular}

${ }^{1}$ Diet $\mathrm{S}=$ Standard diet; Diet $\mathrm{C}=$ cow's milk diet; Diet $\mathrm{G}=$ goat's milk diet. Cholesterol content of the diets (in $\mathrm{mg} / \mathrm{kg}$ of diet): Diet $\mathrm{S}=$ trace; Diet $\mathrm{C}=23.74$; Diet $\mathrm{G}=28.53$.

${ }^{2}$ Protein content for diets $\mathrm{C}$ and $\mathrm{G}$ comprises casein + protein from cow's or goat's milk, respectively.

${ }^{3} \mathrm{MCT}=$ Medium-chain triglycerides.

${ }^{4}$ Mineral and vitamin supplements were formulated taking into account the mineral content of the lyophilized milks to meet the mineral requirements recommended by the American Institute of Nutrition (Reeves et al., 1993). Analysis of lyophylates used (mg/kg of diet): Fat content (cow's milk $=28.76 \%$; goat's milk $=30.69 \%$ ), protein content (cow's milk $=24.84 \%$; goat's milk $=23.36 \%$ ), lactose content (cow's milk $=40.75 \%$; goat's milk $=39.20 \%$ ), and mineral composition (in $\mathrm{mg} / 100 \mathrm{~g}$ of lyophylate): cow's milk $=\mathrm{Ca}, 1030.5 ; \mathrm{P}$, 781.9; $\mathrm{Mg}, 85.25 ; \mathrm{Fe}, 0.87 ; \mathrm{Cu}, 0.14$; and $\mathrm{Zn}, 3.51$; goat's milk $=\mathrm{Ca}$, 1319; P, 813.3; Mg, 89.5; Fe, 1.23; Cu, 0.25; and $\mathrm{Zn}, 4.9$.

copper, magnesium, and zinc (atomic absorption spectrophotometry, Perkin-Elmer 1100B, Shelton, CT), phosphorus (method of Fiske and Subbarow, 1925) and cholesterol [enzymatic kit for food analysis, Boehringer Mannheim (Grossmann et al., 1976)].

\section{Experimental Design}

Three experimental groups were established, each provided with 1 of the 3 types of diet: the standard diet $(n=8)$, the cow's milk diet $(n=10)$, and the diet based on goat's milk $(\mathrm{n}=10)$ (Table 1$)$.

During the treatments with the different types of diet, the animals were weighed and housed in individual ventilated and thermoregulated cages $\left(22 \pm 2^{\circ} \mathrm{C}\right)$ with a 12-h light:dark period. For $2 \mathrm{wk}$, diets and mineral-free water were available ad libitum to all rats. At the end of the experimental period, the rats were weighed after an overnight fast and anesthetized by intraperitoneal injection of $5 \mathrm{mg} / 100 \mathrm{~g}$ of BW of sodium pentobarbital (Sigma Chemical Co., St. Louis, MO). The animals were tested by tail pinch reflex until complete loss of the reflex, and body temperature was maintained at $37^{\circ} \mathrm{C}$ with a thermisor-controlled heated pad. To avoid the effect of fasting motor activity on biliary emp- 
tying, bile collection for all rats in the 3 experimental groups was carried out on the same day and under the same experimental conditions, by selecting one rat consecutively from each experimental group until all bile extractions were complete. After median laparotomy, the common bile duct was isolated and cannulated with PE-10 polyethylene tubing. A bile sample was collected into previously weighed vials for the first $30 \mathrm{~min}$ after cannulation. After the experiments, the rats were totally bled by cannulation of the abdominal aorta and the liver was removed and chilled in ice-cold $\mathrm{NaCl}(9$ $\mathrm{g} / \mathrm{L})$.

\section{Bile Sampling and Analysis}

The volume of bile was determined gravimetrically, assuming a density of $1.0 \mathrm{~g} / \mathrm{mL}$, and bile flow was expressed as microliters per minute per gram of liver. The following bile parameters were evaluated: total biliary acids (measured enzymatically using $3 \alpha$-hydroxysteroid dehydrogenase; Talalay, 1960), total cholesterol (CHOD-PAD method, Spinreact, Girona, Spain; Deeg and Ziegenhorn, 1983), and phospholipids (TrinderCHO method, Spinreact; Takeyama et al., 1977). $3 \alpha-$ Hydroxysteroid dehydrogenase was purchased from Sigma.

\section{Blood Sampling and Analysis}

Blood samples from the abdominal aorta were collected in EDTA tubes (Venoject, Terumo Europe, Leuven, Belgium). Plasma was obtained by centrifugation at $3000 \mathrm{rpm}$ for $15 \mathrm{~min}$ at $4^{\circ} \mathrm{C}$ and stored at $-40^{\circ} \mathrm{C}$ until analysis. The following plasma parameters were evaluated: total cholesterol (CHOD-PAD method, Boehringer Mannheim GmbH Diagnostica; Deeg and Ziegenhorn, 1983), triglycerides (GPO-PAP method, Boehringer Mannheim; Bergmeyer, 1974), and alanine and aspartate aminotransferases (method of Bergmeyer et al., 1978).

\section{Lithogenic Index}

The lithogenic index (cholesterol saturation index) of bile is determined by the molar relation between concentrations of cholesterol, phospholipids, and bile acids, and by the concentration of total lipids. The lithogenic index was calculated from the quotient of the percentage of molar cholesterol in the sample divided by the percentage of molar cholesterol at saturation; the latter value was found with the following thirddegree polynomial function (Thomas and Hofmann, 1973):

Percentage of molar cholesterol at saturation $=3.082$ $-0.804 x+117.05 x^{2}-204.94 x^{3}$, where $x$ is the concentra- tion of phospholipids divided by the sum of the concentrations of bile acids + phospholipids, expressed in moles per liter.

\section{Quality Control}

Given the importance of obtaining an accurate determination of the different parameters studied, a quality control test of these determinations was carried out. This test included the analysis of a set of primary standards and problem samples. Two types of primary standards were examined: those related to each determination and the lyophilized control serum or bile. The results of this test showed that neither the standard deviation of the means between the primary standards nor that corresponding to the problem samples were significant in any case, throughout the experimental period.

\section{Statistical Analysis}

Statistical evaluation was performed by the one-way ANOVA method using SPSS 2002, PC software package (Version 11.5, SPSS Inc., Chicago, IL) to find significant differences among treatments. Differences were considered statistically significant at $P<0.05$.

\section{RESULTS}

\section{Food Intake, Rat Weight, and Liver Weight}

Food intake was similar among the rats given the cow and the goat milk based diets but significantly lower than that for the animals given the standard $\operatorname{diet}(P<0.01$ and 0.001 , respectively). There were no significant differences in final body and liver weights, or in the ratio of liver weight to $\mathrm{BW}$, in relation to the type of diet consumed (Table 2).

\section{Effect of Diet Supply on Bile Secretion}

Bile flow and bile acid secretion under basal conditions are shown in Table 3. Bile flow and bile acid concentration did not differ significantly between the 3 diets assayed. The content of cholesterol in bile was significantly higher for the rats fed the goat's milk diet with respect to those consuming the cow's milk and the standard diets $(P<0.001)$. The phospholipid concentration was similar for the 2 milk-based diets and significantly higher for cow's milk in comparison with the standard diet $(P<0.001)$. The biliary secretion of bile acids and of phospholipids did not significantly differ between the groups. However, there was a significant difference in cholesterol output, this being greater among the animals given the goat's milk diet than 
Table 2. Food intake, BW, and liver weight of rats fed on standard nonmilk or milk diets (cow or goat).

\begin{tabular}{lccccl}
\hline & $\begin{array}{l}\text { Standard } \\
\text { diet } \\
(\mathrm{n}=8)\end{array}$ & $\begin{array}{l}\text { Cow milk } \\
\text { diet } \\
(\mathrm{n}=10)\end{array}$ & $\begin{array}{l}\text { Goat milk } \\
\text { diet } \\
(\mathrm{n}=10)\end{array}$ & RSD $^{1}$ & $\begin{array}{l}\text { Level of } \\
\text { significance }\end{array}$ \\
Item & 17.23 & $14.67^{\mathrm{a}}$ & $13.39^{\mathrm{a}}$ & 2.01 & $* * *$ \\
\hline Food intake $(\mathrm{g})$ & $296.1^{\mathrm{a}}$ & $304.9^{\mathrm{a}}$ & $286.0^{\mathrm{a}}$ & 27.80 & $\mathrm{NS}$ \\
Body weight $(\mathrm{g})$ & $7.63^{\mathrm{a}}$ & $7.33^{\mathrm{a}}$ & $7.22^{\mathrm{a}}$ & 0.80 & NS \\
Liver weight $(\mathrm{g})$ & $25.77^{\mathrm{a}}$ & $24.03^{\mathrm{a}}$ & $25.28^{\mathrm{a}}$ & 1.55 & $\mathrm{NS}$ \\
\hline Liver weight:BW $\times 1000$ & & &
\end{tabular}

${ }^{a}$ Means within the same row without a common superscript differ.

NS = Nonsignificant, $P>0.05$.

$* * * P<0.001$.

${ }^{1} \mathrm{RSD}=$ Residual standard deviation.

among those consuming the cow's milk diet $(P<0.001)$ and the standard diet $(P<0.01)$. Lithogenic index of bile did not differ significantly between the 3 diets assayed (Table 3). The ratio of biliary phospholipid output to bile acids output did not differ significantly among the 3 diets studied. The ratio of biliary cholesterol output to bile acid output plus biliary phospholipids output was significantly lower in the cow's milk group than in the goat's milk group $(P<0.001)$ and in the standard diet group $(P<0.05)$ (Table 3$)$.

\section{Effect of Diet Supply on Plasma Parameters}

Table 4 shows the results obtained from the analyses of the plasma of the 3 groups of rats. Among the animals fed the goat's milk-based diet, cholesterol values were significantly lower with regard to the standard $(P<$ $0.05)$ and the cow's milk diets $(P<0.001)$. Triglyceride concentrations were lower with the goat milk-based diet than with the cow milk diet $(P<0.05)$ and similar to those found with the standard diet. Alanine aminotransferase and aspartate aminotransferase did not vary among the 3 diets, except for aspartate aminotransferase between the cow's milk and standard diets $(P<0.01)$.

\section{DISCUSSION}

This study shows that the dietary intake of goat's milk, compared with that of cow's milk, induces a number of changes in plasma lipids and bile output in rats. The decrease in plasma cholesterol and triglyceride concentrations observed with the diet based on goat's milk had the most pronounced effect on plasma lipids. With regard to biliary secretion, the most important result was the increase in cholesterol output.

The lower food intake of the rats fed the milk-based diets, compared with that of those on the standard diet,

Table 3. Bile composition and parameters in bile of rats fed on standard nonmilk or milk diets (cow or goat).

\begin{tabular}{lccccc}
\hline & $\begin{array}{l}\text { Standard } \\
\text { diet } \\
(\mathrm{n}=8)\end{array}$ & $\begin{array}{l}\text { Cow milk } \\
\text { diet } \\
(\mathrm{n}=10)\end{array}$ & $\begin{array}{l}\text { Goat milk } \\
\text { diet } \\
(\mathrm{n}=10)\end{array}$ & $\mathrm{RSD}^{1}$ & $\begin{array}{l}\text { Level of } \\
\text { significance }\end{array}$ \\
\hline Btem & $1.680^{\mathrm{a}}$ & $1.542^{\mathrm{a}}$ & $1.590^{\mathrm{a}}$ & 0.35 & $\mathrm{NS}$ \\
Tile flow $(\mu \mathrm{L} / \mathrm{min}$ per g of liver) & $33.31^{\mathrm{a}}$ & $32.62^{\mathrm{a}}$ & $36.59^{\mathrm{a}}$ & 5.85 & $\mathrm{NS}$ \\
Bile acid output (mmol/min per g of liver) & $56.16^{\mathrm{a}}$ & $61.83^{\mathrm{a}}$ & $57.19^{\mathrm{a}}$ & 16.38 & $\mathrm{NS}$ \\
Cholesterol concentration (mmol/L) & 0.677 & 0.558 & 0.840 & 0.07 & $* * *$ \\
Cholesterol output (mmol/min per g of liver) & $0.987^{\mathrm{a}}$ & $0.863^{\mathrm{a}}$ & 1.340 & 0.17 & $* * *$ \\
Phospholipids concentration (mmol/L) & $6.010^{\mathrm{a}}$ & $7.744^{\mathrm{b}}$ & $6.977^{\mathrm{ab}}$ & 1.07 & $*$ \\
Phospholipids output (mmol/min per g of liver) & $11.27^{\mathrm{a}}$ & $11.91^{\mathrm{a}}$ & $11.26^{\mathrm{a}}$ & 2.62 & $\mathrm{NS}$ \\
Lithogenic index $_{\text {PLO/BAO }}^{2}$ & $0.303^{\mathrm{a}}$ & $0.271^{\mathrm{a}}$ & $0.301^{\mathrm{a}}$ & 0.03 & $\mathrm{NS}$ \\
CO/BAO+PLO & $0.210^{\mathrm{a}}$ & $0.204^{\mathrm{a}}$ & $0.207^{\mathrm{a}}$ & 0.04 & $\mathrm{NS}$ \\
\hline
\end{tabular}

${ }^{\mathrm{a}, \mathrm{b}}$ Means within the same row without a common superscript differ.

NS = Nonsignificant, $P>0.05$.

$* P<0.05$.

$* * * P<0.001$.

${ }^{1} \mathrm{RSD}=$ Residual standard deviation.

${ }^{2} \mathrm{PLO} / \mathrm{BAO}=$ Phospholipids output/bile acid output.

${ }^{3} \mathrm{CO} / \mathrm{BAO}+\mathrm{PLO}=$ Cholesterol output/bile acid output + phospholipids output. 
Table 4. Cholesterol, triglycerides, $\mathrm{ALT},{ }^{1}$ and $\mathrm{AST}^{2}$ in serum of rats fed on standard nonmilk or milk diets (cow or goat).

\begin{tabular}{lccccl}
\hline & $\begin{array}{l}\text { Standard } \\
\text { diet } \\
(\mathrm{n}=8)\end{array}$ & $\begin{array}{l}\text { Cow milk } \\
\text { diet } \\
(\mathrm{n}=10)\end{array}$ & $\begin{array}{l}\text { Goat milk } \\
\text { diet } \\
(\mathrm{n}=10)\end{array}$ & $\mathrm{RSD}^{3}$ & $\begin{array}{l}\text { Level of } \\
\text { significance }\end{array}$ \\
\hline Cholesterol (mg/dL) & 63.9 & 70.1 & 58.4 & 6.46 & $* *$ \\
Triglycerides (mg/dL) & $56.6^{\mathrm{ab}}$ & $60.8^{\mathrm{a}}$ & $49.6^{\mathrm{b}}$ & 7.69 & $*$ \\
ALT (IU/L) & $38.6^{\mathrm{a}}$ & $35.3^{\mathrm{a}}$ & $38.1^{\mathrm{a}}$ & 9.38 & NS \\
AST (IU/L) & $129.0^{\mathrm{a}}$ & $102.3^{\mathrm{b}}$ & $109.1^{\mathrm{ab}}$ & 27.31 & $*$ \\
\hline
\end{tabular}

${ }^{\mathrm{a}, \mathrm{b}}$ Means within the same row without a common superscript differ.

NS $=$ Nonsignificant, $P>0.05$.

$* P<0.05$.

$* * P<0.01$

${ }^{1} \mathrm{ALT}=$ Alanine aminotransferase.

${ }^{2} \mathrm{AST}=$ Aspartate aminotransferase.

${ }^{3} \mathrm{RSD}=$ Residual standard deviation.

has been reported previously for the goat's milk-based diet (Alférez et al., 2001; López-Aliaga et al., 2003). Taking into account that the 3 diets have the same protein (20\%) and fat (10\%) levels, the lower food intake in the rats fed the milk-based diets would seem to be due to the different organoleptic characteristics conferred by the lyophylate used in their preparation, especially concerning the goat's milk-based diet.

Despite the lower food intake for the milk-based diets, no statistically significant differences were recorded concerning the final $\mathrm{BW}$ or the liver weight for the 3 experimental groups. Thus, the liver weight:BW ratio was similar for all animals.

Our results, in accordance with those obtained in a previous study (Alférez et al., 2001), show that consumption of goat's milk, compared with cow's milk, decreases plasma cholesterol concentrations in rats. This effect is partly due to the higher levels of MCT in goat's milk (34\%) compared with cow's milk (21\%), as the presence of MCT in the diet reduces the synthesis of endogenous cholesterol and its intestinal absorption (García Unciti, 1996). Moreover, goat's milk fat has higher monounsaturated fatty acid content than does cow's milk (Haenlein, 2001) and these fatty acids are known to have a hypocholesterolemic effect (KrisEtherton and $\mathrm{Yu}, 1997)$. However, in our previous study, we were unable to elucidate whether the reduction in plasma cholesterol concentrations after goat milk consumption was due to a higher elimination rate of cholesterol or to its redistribution in the animal's body.

Under our experimental conditions, the hypocholesterolemic effect is due to the higher cholesterol output in bile, which was significantly greater among the rats fed the goat's milk-based diet, a consequence particularly due to the type of fat in this milk. We believe, therefore, that this effect was not the result of a redistri- bution of the cholesterol in the animal's body, but to a higher biliary output of such cholesterol, as shown in this study. Moreover, dietary fat is known to influence lipid metabolism (Feoli et al., 2003).

A further consideration is that the hepatic synthesis of cholesterol destined for bile is selectively affected by the diet, as shown by Villalon et al. (1987). The higher cholesterol concentrations found in the bile of animals fed the goat's milk or standard diets, with respect to the cow's milk diet, and the higher cholesterol output in the bile of rats fed the goat's milk diet compared to the other 2 diets, are due to the different quality of the fats used in these experimental diets. Bravo et al. (1998) demonstrated the influence of dietary fat on the biliary excretion of cholesterol in the rat, indicating that feeding monounsaturated fatty acids compared with SFA results in the more rapid excretion of cholesterol originating from the diet via the bile.

Probably, as has been described for dietary fish oil (Smit et al., 1991), the fat from goat's milk induces changes in the transport and metabolic pathways of cholesterol in the rat liver, which results in a more rapid disposition of plasma-derived cholesterol into the bile. To gain further insight into the metabolic changes induced by dietary goat's milk, we must investigate its effects on the metabolism of hepatic cholesterol.

The increased concentration of cholesterol in bile, coupled with reduced secretion of bile acids, causes an increase in the extent to which bile is saturated in cholesterol (Kesaniemi, 1996), and this can be measured using the lithogenic index (Metzger et al., 1972). In our experiments, the consumption of the goat's milk and the standard diets produced only a slight increase in the lithogenic index with respect to the cow's milk diet. On the other hand, Lafont et al. (1985) reported no significant variation in the biliary secretion of phospholipids and an increase in the lithogenic index of 
bile, as occurred under our experimental conditions, in which there were no significant differences concerning the output of phospholipids. Thus, the lithogenic index was slightly higher for the goat's milk diet than for the cow's milk diet, but this finding lies within the range of normal values reported in the references consulted (García-Diez et al., 1996; Bravo et al., 1998). Moreover, it is similar to the results obtained with the standard diet based on an olive oil fat source, and it is well known that this oil does not alter the lithogenic index (Bravo et al., 1998).

The slight increase observed in the lithogenic index after providing dietary fats with a proven antiatherogenic effect, as occurred under our experimental conditions with the animals given the goat's milk diet, has been described by other authors. Smit et al. (1991) reported that the lithogenic index of bile was slightly higher for a group of rats fed a diet based on fish oil compared with those fed a diet based on corn oil.

Consumption of the goat's milk-based diet led to lower plasma triglycerides concentrations compared with the cow's milk diet, similar to those of the standard diet (in which the fat source is olive oil). This could be due to the favorable fatty acids profile derived from the goat's milk fat vs. cow's milk fat, with slightly higher mono- and polyunsaturated fatty acids content (Haenlein, 2001), the effect of which (in decreasing plasma triglycerides concentrations) has been widely described. On the other hand, the higher content of antioxidant elements (Alférez et al., 2003) and enzymes in goat's milk (Debski et al., 1987) could contribute to modification of plasma lipids. Gorinstein et al. (2002) found that the positive influence on plasma lipids was significantly higher in the group of rats fed the oil that had the greatest antioxidant potential.

In summary, the results reported in this study show that supplying goat's milk in the diet rather than cow's milk leads to an increase in the biliary secretion of cholesterol and a decrease in plasma cholesterol concentration. The outputs of phospholipids and bile acids, and the lithogenic index remained within normal values. Moreover, consumption of this type of milk lowers plasma concentration of triglycerides and therefore has a positive effect similar to that of virgin olive oil (standard diet) on the lipid metabolism.

\section{ACKNOWLEDGMENTS}

This study was supported by the Interministerial Commission of Science and Technology, Madrid, Spain (Project AGL2000-1501). We thank Elisa Alcover for her efficient administrative support and Rosa Jiménez for her competent technical assistance.

\section{REFERENCES}

Alférez, M. J. M., M. Barrionuevo, I. López-Aliaga, M. R. Sanz-Sampelayo, F. Lisbona, J. C. Robles, and M. S. Campos. 2001. Digestive utilization of goat and cow milk fat in malabsorption syndrome. J. Dairy Res. 68:451-461.

Alférez, M. J. M., I. López-Aliaga, M. Barrionuevo, and M. S. Campos. 2003. Effect of dietary inclusion of goat milk on the bioavailability of zinc and selenium in rats. J. Dairy Res. 70:181-187.

AOAC. 1990. Official Methods of Analysis. 15th ed. Association of Official Analytical Chemists, Arlington, VA.

Bergmeyer, H. U. 1974. Methoden der enzymatischen analyse, 3rd ed. Verlag Chemie, Weinheim, Germany.

Bergmeyer, H. U., P. Scheibe, and A. W. Wahlefeld. 1978. Optimization of methods for aspartate aminotransferase and alanine aminotransferase. Clin. Chem. 24:58-73.

Berner, L. A. 1993. Roundtable discussion on milk fat, dairy foods, and coronary heart disease risk. J. Nutr. 123:1175-1184.

Bravo, E., L. Flora, A. Cantafora, V. de Luca, M. Tripodi, M. Avella, and K. M. Botham. 1998. The influence of dietary saturated and unsaturated fat on hepatic cholesterol metabolism and the biliary excretion of chylomicron cholesterol in the rat. Biochim. Biophys. Acta 1390:134-148.

Debski, B., M. F. Picciano, and J. A. Milne. 1987. Selenium content and distribution of human, cow and goat milk. J. Nutr. 117:1091-1097.

Deeg, R., and J. Ziegenhorn. 1983. Kinetic enzymic method for automated determination of total cholesterol in serum. Clin. Chem. 10:1798-1802.

During, A., N. Combe, S. Mazette, and B. Entressangles. 2000. Effects of cholesterol balance and LDL cholesterol in the rat of a softripened cheese containing vegetable oils. J. Am. Coll. Nutr. 19:458-466.

Feoli, A. M., C. Roehring, L. N. Rotta, A. H. Kruger, K. B. Souza, A. M. Kessler, S. V. Renz, A. M. Brusque, K. B. Souza, and M. L. S. Perry. 2003. Serum and liver lipids in rats and chicks fed with diets containing different oils. Nutrition 19:789-793.

Fiske, C. H., and Y. Subbarow. 1925. The colorimetric determination of phosphorus. J. Biol. Chem. 66:375-400.

García-Diez, F., V. García-Mediavilla, J. E. Bayón, and J. GonzálezGallego. 1996. Pectin feeding influences fecal bile acid excretion, hepatic bile acid and cholesterol synthesis and serum cholesterol in rats. J. Nutr. 126:1766-1771.

García Unciti, M. S. 1996. Utilidad terapéutica de los triglicéridos de cadena media (MCT). Dietas cetogénicas en la epilepsia infantil. Nutrición Clínica 16:7-35.

Gorinstein, S., H. Leontowicz, A. Lojek, M. Leontowicz, M. Ciz, R. Krzeminski, M. Gralak, J. Czerwinski, Z. Jastrzebski, S. Trakhtenberg, N. Grigelmo-Miguel, R. Soliva-Fortuny, and O. MartinBelloso. 2002. Olive oils improve lipid metabolism and increase antioxidant potential in rats fed diets containing cholesterol. J. Agric. Food Chem. 50:6102-6108.

Grossman, A., H. Timmen, and H. Klostermeyer. 1976. Die enzymatische bestimmung von cholesterin in milchfett-eine alternative $\mathrm{zu}$ den bisher gebräuchlichen methoden. Milchwissenschaft 31:721-724.

Haenlein, G. F. W. 2001. Past, present and future perspectives of small ruminant dairy research. J. Dairy Sci. 84:2097-2115.

Kesaniemi, Y. A. 1996. Genetics and cholesterol metabolism. Curr. Opin. Lipidol. 7:124-131.

Kris-Etherton, P. M., and S. Yu. 1997. Individual fatty acid effects on plasma lipids and lipoproteins: human studies. Am. J. Clin. Nutr. 65(Suppl.):1628-1644.

Lafont, H., D. Lairon, J. L. Vigne, F. Chanussot, C. Chabert, H. Portugal, A. M. Pauli, C. Crotte, and J. C. Hauton. 1985. Effect of wheat bran, pectin and cellulose on the secretion of bile in rats. J. Nutr. 115:849-855.

López-Aliaga, I., M. J. M. Alférez, M. Barrionuevo, T. Nestares, M. R. Sanz-Sampelayo, and M. S. Campos. 2003. Study of nutritive utilization of protein and magnesium in rats with resection of the distal small intestine. Beneficial effect of goat milk. J. Dairy Sci. 86:2958-2966. 
Metzger, A. L., S. Heymfield, and S. M. Grundy. 1972. The lithogenic index: A numerical expression for the relative lithogenicity of bile. Gastroenterology 62:499-501.

Ministerio de Agricultura Pesca y Alimentación (MAPA). 2004. La alimentación en España, ed. MAPA, Madrid, Spain.

Nakano, A., P. S. Tietz, and N. F. La Russo. 1990. Circadian rhythms of biliary protein and lipid excretion in rats. Am. J. Physiol. 258:G653-G659.

Redgrave, T. G. 1983. Formation and metabolism of chilomicrons. Int. Rev. Physiol. 28:103-130.

Reeves, P. G., F. H. Nielsen, and G. C. Fahey. 1993. AIN-93 Purified diets for laboratory rodents: Final report of the American Institute of Nutrition and ad hoc writing committee on the reformulation of the AIN-76A rodent diet. J. Nutr. 123:1939-1951.

Smit, M. J., A. M. Temmerman, H. Wolters, F. Kuipers, A. C. Beynen, and R. J. Vonk. 1991. Dietary fish oil-induced changes in intrahe- patic cholesterol transport and bile acid synthesis in rats. J. Clin. Invest. 88:943-951.

Takeyama, M., S. Itoh, T. Nayasaki, and I. Tanimazu. 1977. A new enzymatic methods for determination of serum choline-containing phospholipids. Clin. Chem. Acta 79:93-98.

Talalay, P. 1960. Enzymatic analysis of steroid hormones. Meth. Biochem. Anal. 8:119-143.

Thomas, P. J., and A. F. Hofmann. 1973. A simple calculation of the lithogenic index of bile: Expressing biliary lipid composition on rectangular coordinates. Gastroenterology 65:698-700.

Turley, S. D., and J. M. Dietschy. 1988. Cholesterol metabolism and excretion. Pages 617-641 in The Liver: Biology and Pathobiology. I. M. Arias, W. B. Jackoby, H. Popper, D. Schachter, and D. A. Shafritz, ed. Raven Press, New York, NY.

Villalon, L., B. Tuchweber, and I. M. Yousef. 1987. Effect of low protein diet on bile flow and composition in rats. J. Nutr. 117:678-683. 